\title{
174. Paramagnetic Redox Stages of a Bisphane: An ESR and ENDOR Study
}

\author{
by Fabian Gerson* and Markus Scholz \\ Institut für Physikalische Chemie der Universität, Klingelbergstrasse 80, CH-4056 Basel \\ and Armin de Meijere and Burkhard König \\ Institut für Organische Chemie der Georg-August-Universität, Tammannstrasse 2, D-3400 Göttingen \\ and Jürgen Heinze and Klaus Meerholz \\ Institut für Physikalische Chemie der Universität, Albertstrasse 21, D-7800 Freiburg
}

(14.IX.92)

Seven redox stages, the dication $\mathbf{1}^{2+}$, the radical cation $1^{+}$, the neutral 1 , the radical anion $\mathbf{1}^{-}$, the dianion $\mathbf{1}^{2-}$, the radical trianion $1^{3-}$, and the tetraanion $1^{4-}$, are indicated by cyclic voltammetry for the bisphane 1 , in which the benzene decks of two lateral paracyclophane moieties are orthogonal to the plane of anthracene framework. In $1^{+}$ and $\mathbf{1}^{-}$, the unpaired electron is accommodated into the central anthracene subsystem, and the same statement holds for the two positive or negative charges in $\mathbf{1}^{2+}$ and $\mathbf{1}^{2-}$. Formation of $\mathbf{1}^{3-}$ and $\mathbf{1}^{4-}$ occurs through admission of additional electrons one-by-one into the two paracyclophane moieties flanking the doubly charged anthracene subsystem in $\mathbf{1}^{2-}$. The above-postulated, successive release or uptake of electrons by the individual parts of the bisphane is in perfect accord with the hyperfine data determined by ESR and ENDOR spectroscopy for $1^{+}, 1^{-}$, and $\mathbf{1}^{3-}$, as well as for radical ions of suitable reference compounds.

Introduction. - Recently, synthesis of bis-2,3:6,7-[1,2-benzo[2.2]paracyclophane-1,9dieno]-9,10-dihexylanthracene (1), here denoted bisphane, has been reported [1]. In these molecules, the benzene decks of the two lateral [2.2]paracyclophane moieties are orthogonal to the plane of the anthracene framework, and there is essentially no conjugation between the three subsystems. As a consequence, each of these subsystems can be almost independently reduced or oxidized, according to its individual redox potentials. This situation is reminiscent of that encountered with Ph-substituted 1,2:9,10dibenzo[2.2]paracyclophane-1,9-dienes which have two lateral biphenyl or terphenyl moieties orthogonal to the benzene decks of the central [2.2]paracyclophane subsystem [2]. In [1], four one-electron reduction potentials have been reported for 1 . They are attributed to the uptake of two electrons into the central anthracene subsystem, followed by the admission of two more electrons into the lateral paracyclophane moieties. Subsequent observation of two one-electron oxidation potentials of 1 increases the number of redox stages from five to seven; these include the dication $\mathbf{1}^{2+}$, the radical cation $\mathbf{1}^{+}$, the neutral compound 1 , the radical anion $1^{-}$, the dianion $1^{2-}$, the radical trianion $1^{3-}$, and the tetraanion $\mathbf{1}^{4-}$. In the present work, the three doublet-state species, $\mathbf{1}^{+}, \mathbf{1}^{-}$, and $\mathbf{1}^{3-}$, are characterized by their hyperfine data with the use of ESR and ENDOR spectroscopy. The spin multiplicity of $\mathbf{1}^{4-}$, which possibly has a ground or low-lying excited triplet state, could not be experimentally verified for reasons given below. The redox potentials of 1 and the hyperfine data for $1^{+}, \mathbf{1}^{-}$, and $\mathbf{1}^{3-}$ are compared with the corresponding values of 9,10-dibutylanthracene (2) and 1,2:9,10-dibenzo[2.2]paracyclophane-1,9-diene (3) which form radical ions structurally related to the three paramagnetic stages of $\mathbf{1}$. 


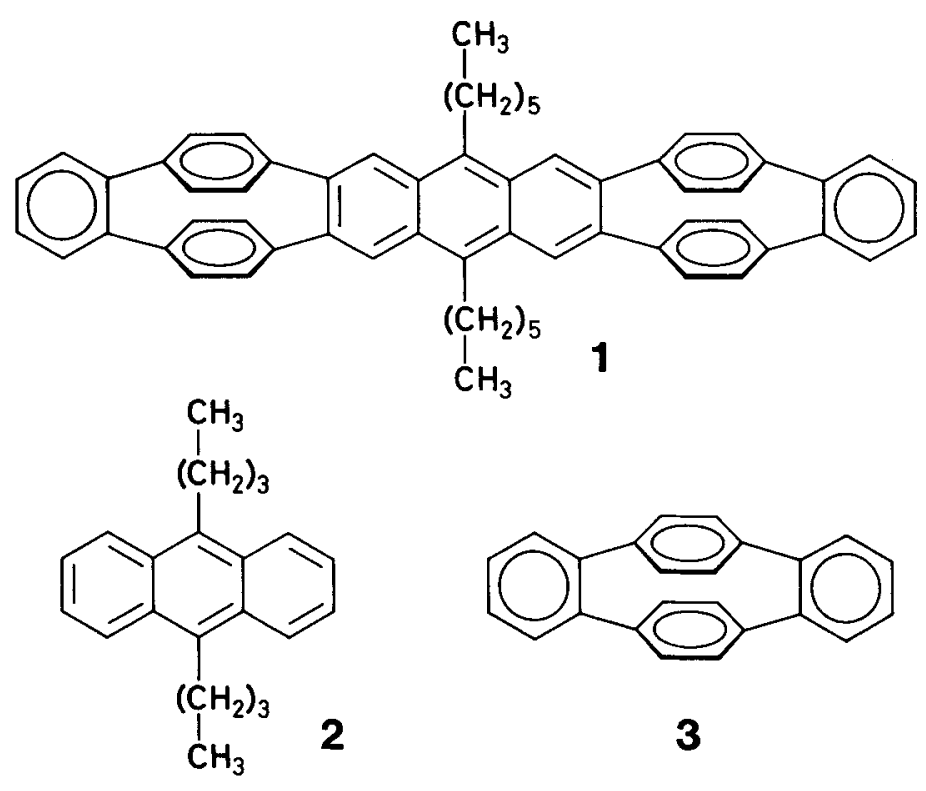

Results and Discussion. - Redox Potentials. Table 1 lists the oxidation and reduction potentials obtained for $\mathbf{1}-\mathbf{3}$ by cyclic voltammetry. The four values involving the redox steps $1^{2+} / \mathbf{1}^{\dagger}, \mathbf{1}^{+} / \mathbf{1}, \mathbf{1} / \mathbf{1}^{-}$, and $\mathbf{1}^{-} / \mathbf{1}^{2-}$ resemble the analogous data for $2^{2+} / \mathbf{2}^{+}, 2^{\dagger} / 2,2 / 2^{-}$, and $\mathbf{2}^{-} / \mathbf{2}^{2-}$, in accordance with the successive release or uptake of two electrons by the anthracene subsystem of 1 . As in the next redox step, $\mathbf{1}^{2-} / \mathbf{1}^{3-}$, an extra electron ought to be accommodated into a paracyclophane moiety, the third reduction potential of 1 should be comparable to the first one of $\mathbf{3}$, at which this compound is converted to $3^{-}$. The substantially more negative value for $\mathbf{1}^{2-} / \mathbf{1}^{3-}$ than for $3 / 3^{-}$is presumably due to the presence of two negative charges in the anthracene subsystem, so that the uptake of an electron by the dianion $\mathbf{1}^{2-}$ to yield the trianion $\mathbf{1}^{3-}$ is more difficult than the reduction of the neutral 3 to its monoanion $3^{-}$. In this respect, it is worth mentioning that [2.2]paracyclophane itself is reduced at almost the same potential $(-3.00 \mathrm{~V} v$ s. SCE [3]) as $\mathbf{1}^{2-}$ to $\mathbf{1}^{3-}$. In the further redox step, $\mathbf{1}^{3-} / \mathbf{1}^{4-}$, the fourth extra electron presumably enters the phane moiety other than that bearing an unpaired electron in $\mathbf{1}^{3-}$, as such a step leads to less electrostatic repulsion than placing a second negative charge in the same moiety.

Table 1. Half-Wave Redox Potentials (in $\mathrm{V}^{\mathrm{a}}$ ) vs. $\mathrm{Ag} / \mathrm{AgCl}$ ) of $\mathbf{1}$ ([1] and this work), 2 (this work), and 3 ([2] and this work). The values in italics refer to potential peaks of irreversible waves. See Experimental for conditions.

\begin{tabular}{lllllll}
\hline Redox step & $\mathbf{1}^{2+} / \mathbf{1}^{+}$ & $\mathbf{1}^{+} / \mathbf{1}$ & $\mathbf{1} / \mathbf{1}^{-}$ & $\mathbf{1}^{-} / \mathbf{1}^{2-}$ & $\mathbf{1}^{2-} / \mathbf{1}^{3-}$ & $\mathbf{1}^{3-} / \mathbf{1}^{4-}$ \\
& +1.79 & +1.03 & -1.93 & -2.43 & -3.03 & -3.10 \\
Redox step & $\mathbf{2}^{2+} / \mathbf{2}^{+}$ & $\mathbf{2}^{+} / \mathbf{2}$ & $\mathbf{2} / \mathbf{2}^{-}$ & $\mathbf{2}^{-} / \mathbf{2}^{2-}$ & & \\
& +1.86 & +1.17 & -2.00 & -2.57 & & \\
Redox step & & & & & $\mathbf{3 / 3 ^ { - }}$ & $\mathbf{3}^{-} / \mathbf{3}^{2-}$ \\
& & & & -2.68 & -2.98 \\
\hline
\end{tabular}

a) Experimental error: $\pm 0.02 \mathrm{~V}$. 


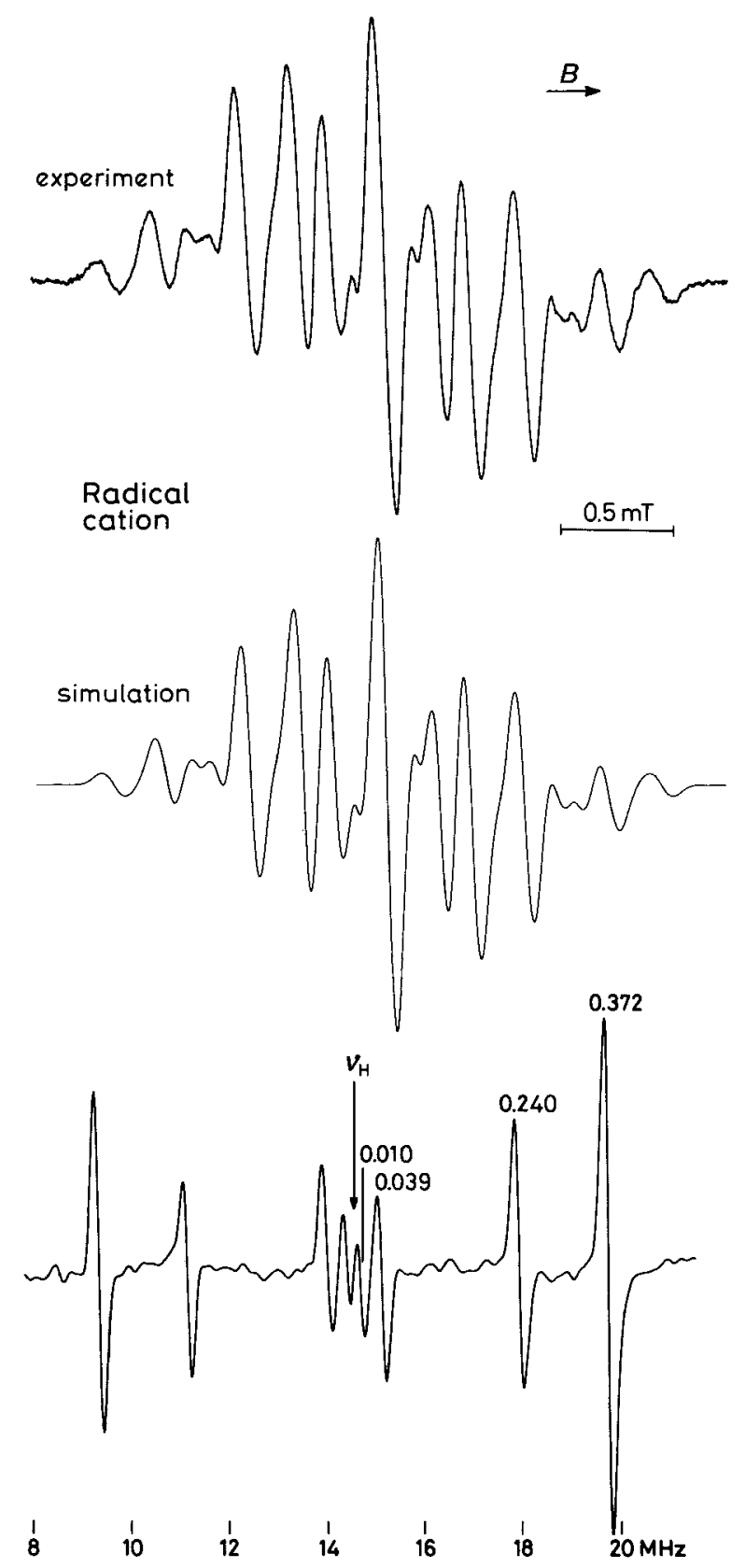

Fig. 1. ESR and proton-ENDOR spectra of $1^{\dagger}$. Solvent: $\mathrm{CH}_{2} \mathrm{Cl}_{2} ;$ temp.: $208 \mathrm{~K}$. The simulation of the ESR spectrum (top) made use of the coupling constants given in Fig. 3; line-shape: Gaussian; line-width: $0.06 \mathrm{mT}$. The numbers above the ENDOR signals are the coupling constants, in $\mathrm{mT}$, associated with these signals. 


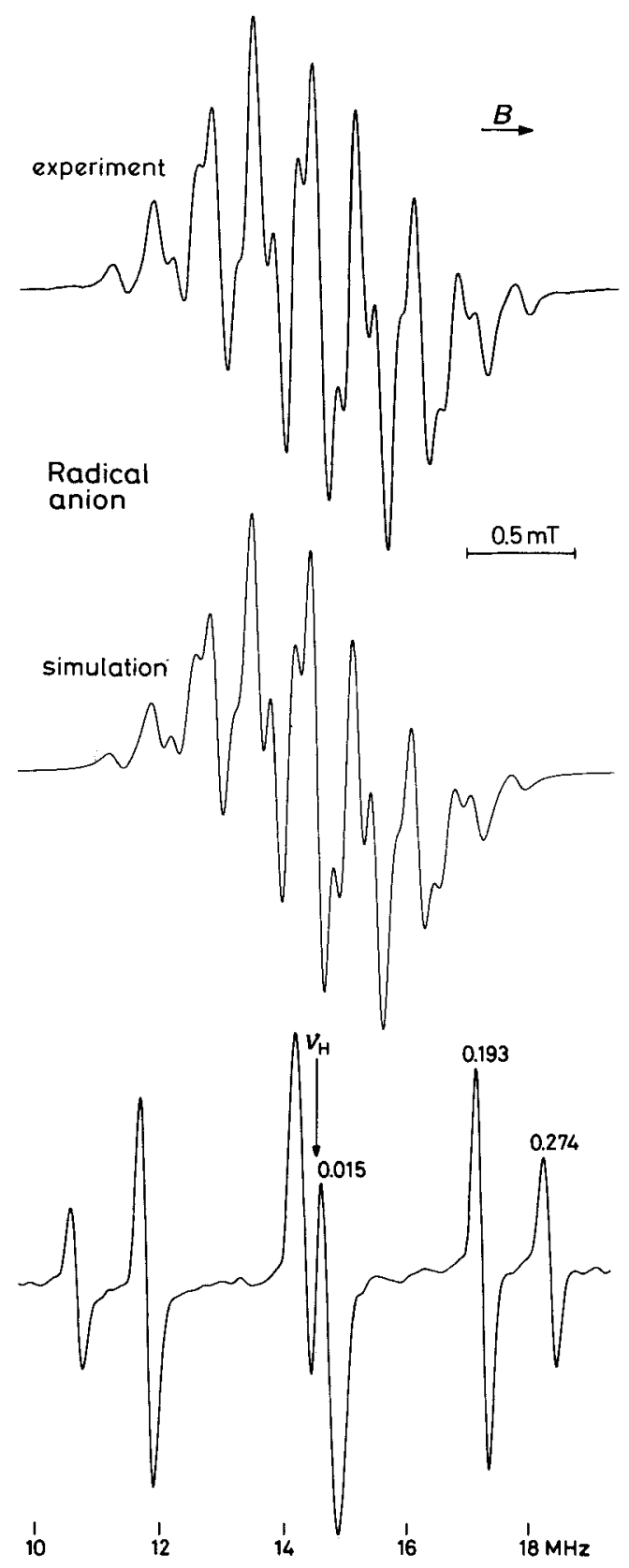

Fig. 2. ESR and proton-ENDOR spectra of $1^{-}$. Solvent: DME; counterion: $\mathrm{K}^{+}$; temp.: $228 \mathrm{~K}$. The simulation of the ESR spectrum (top) made use of the coupling constants given in Fig. 3; line-shape: Lorentzian; line-width: 0.10 $\mathrm{mT}$. The numbers above the ENDOR signals are the coupling constants, in $\mathrm{mT}$, associated with these signals. 


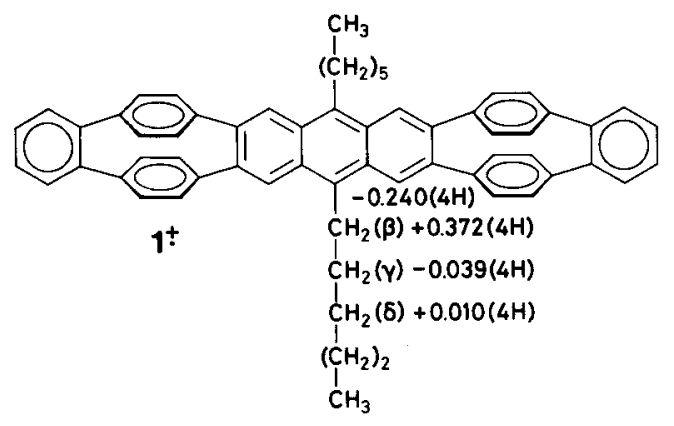<smiles>CCCCc1c2ccccc2c(CC)c2cc(OCC)cc(OCC)c12</smiles>

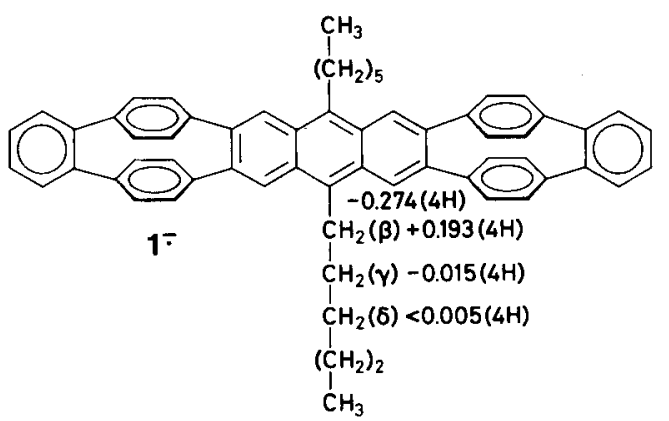

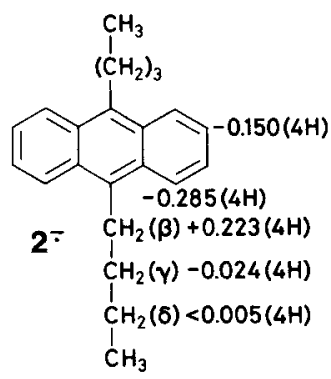<smiles>CCc1c2cc(-c3ccccc3)c(-c3ccccc3)cc2c(CC)c2cc(-c3ccccc3)c(-c3ccccc3)cc12</smiles>

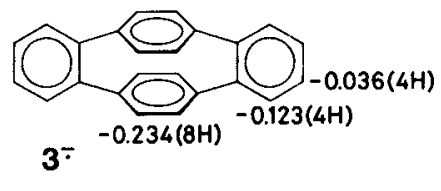

Fig. 3. Proton-coupling constants $[\mathrm{mT}]$ for $\mathbf{1}^{\dagger}, \mathbf{1}^{-}, \mathbf{1}^{3-}, \mathbf{2}^{+}, \mathbf{2}^{-}$(this work), and $\mathbf{3}^{-}$[9]. Experimental error: \pm 0.002 and $\pm 0.001 \mathrm{mT}$ for the absolute values larger and smaller, respectively, than $0.1 \mathrm{mT}$. When no general-TRIPLE resonance spectra could be observed, the signs of the coupling constants are given in parentheses. $n \mathrm{H}$ means an undetermined number of interacting protons.

This assumption is consistent with the fact that the difference in potentials between the redox steps $1^{2-} / \mathbf{1}^{3-}$ and $\mathbf{1}^{3-} / \mathbf{1}^{4-}(0.07 \mathrm{~V})$ is much smaller than the one between $3 / 3^{-}$and $3^{-} / \mathbf{3}^{2-}(0.30 \mathrm{~V})$.

Radical Ions. The radical cation $\mathbf{1}^{+}$was generated by oxidation of the bisphane 1 with $\mathrm{AlCl}_{3}$ in $\mathrm{CH}_{2} \mathrm{Cl}_{2}$, while reduction of 1 with $\mathrm{K}$ in 1,2-dimethoxyethane (DME), 2-methyltetrahydrofuran (MTHF), or in a mixture DME/ $N, N, N^{\prime}, N^{\prime}, N^{\prime \prime}, N^{\prime \prime}$ - hexamethylphosphoric triamide yielded the radical anion $\mathbf{1}^{\top}$. Figs. 1 and 2 show the ESR and ENDOR spectra of $1^{+}$and $1^{-}$. The proton-coupling constants, which do not markedly depend on the solvent and temperature, are given in Fig. 3 together with the corresponding values for the radical ions $2^{+}$and $2^{-}$produced from dibutylanthracene 2 under the same conditions as $1^{+}$and $\mathbf{1}^{-}$ ( $g=2.0026 \pm 0.0001$ for all four species). The signs of the coupling constants were determined by general-TRIPLE resonance spectroscopy [4], taking for granted that those 


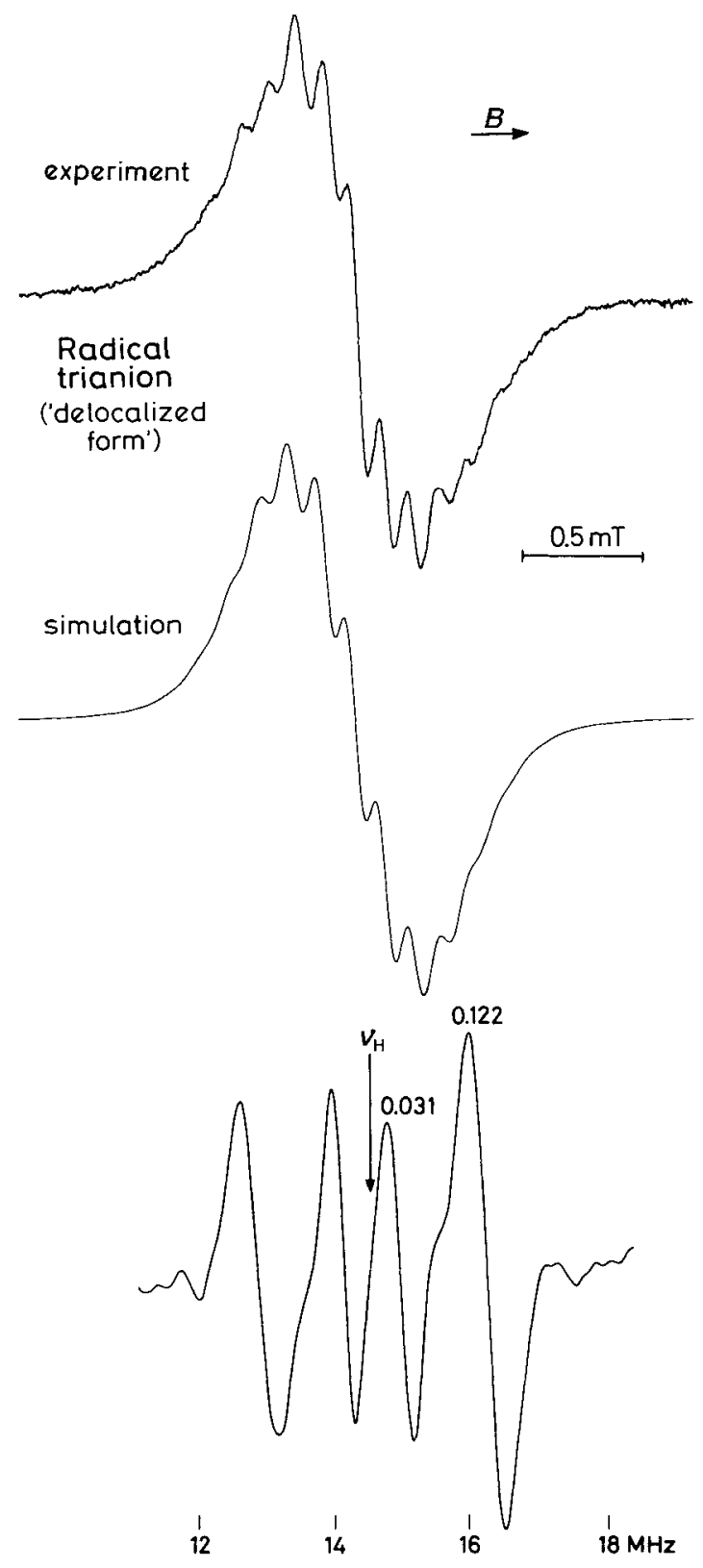

Fig. 4. ESR and proton-ENDOR spectra of $\mathbf{1}^{3-}$. Solvent: DME; counterions: $\mathrm{K}^{+}$; temp.: $213 \mathrm{~K}$. The simulation of the ESR spectrum (top) made use of the coupling constants given in Fig. 3; line-shape: Lorentz ian; line-width 0.12 $\mathrm{mT}$. (As the line-width greatly exceeds the smaller coupling constant $(0.031 \mathrm{mT})$, the simulation does not depend on how many protons are responsible for this constant.) The numbers above the ENDOR signals are the coupling constants, in $\mathrm{mT}$, associated with these signals. 
charges, while an unpaired electron is accommodated into one of the lateral paracyclophane moieties. Under the conditions used for the recording of these spectra, the electron exchange between the two equivalent phane moieties is fast on the hyperfine time-scale $\left(\mathrm{ca} .10^{7} \mathrm{~s}^{-1}\right)$, so that spin population appears to be evenly delocalized over both moieties. The frequency of such an exchange is determined by the rate of counterion migration between two preferred equivalent sites of the negative charge in the radical anion [10-12]. This rate depends, inter alia, on concentration of the counterions and can be slowed down by continuing the reduction process. In fact, when the contact of the solution of $1^{3-}$ with $\mathrm{K}$ mirror was maintained, every second component of the sixteenproton hyperfine pattern in the ESR spectrum of $1^{3-}$ became gradually weaker, indicating a transition to an eight-proton pattern spaced by a twice as large coupling constant which is diagnostic of spin localization on one paracyclophane moiety (for similar phenomenon, see [10]). The final ESR spectrum then observed is reproduced in Fig. 5 ; the corresponding ENDOR signals could not be detected at this stage.

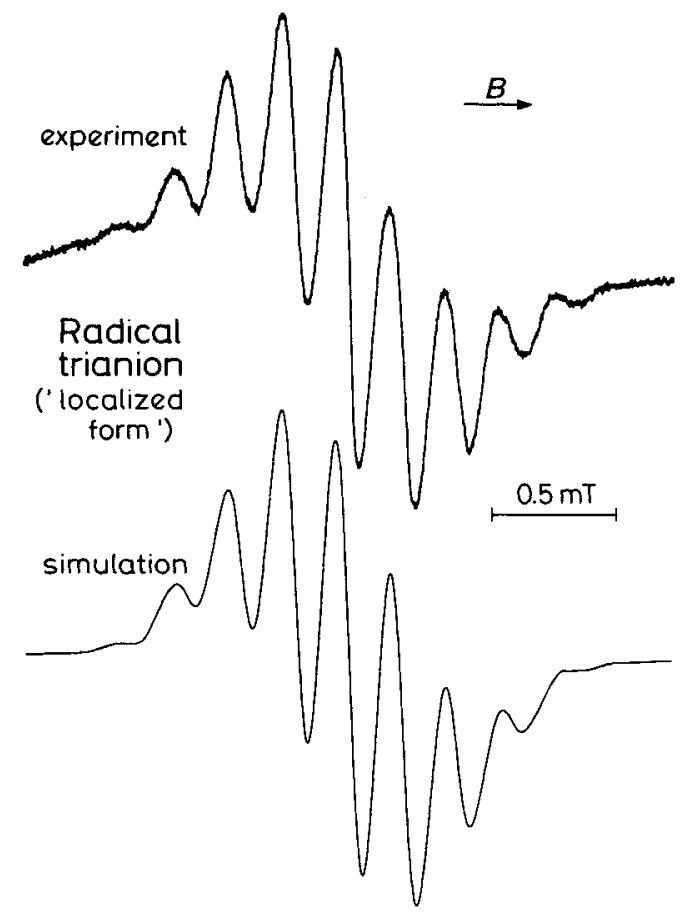

Fig. 5. ESR Spectrum of $1^{3-}$ observed upon prolonged contact with $K$ mirror. Experimental conditions as for the spectrum in Fig. 4. The simulation made use of the coupling constant $0.22 \mathrm{mT}(8 \mathrm{H})$; line-shape: Gaussian; line-width: $0.20 \mathrm{mT}$.

According to the cyclic voltammogram of 1 (Table 1), exhaustive reduction of this compound ultimatively leads to the tetraanion $\mathbf{1}^{4-}$, in which two electrons should be located one-by-one in the relatively remote paracyclophane moieties (see above). Thus, a ground or low-lying triplet state is expected for $\mathbf{1}^{4-}$. To detect such a state by ESR spectroscopy, exposure of a MTHF solution of $\mathbf{1}^{3-}$ to the metallic mirror at $195 \mathrm{~K}$ was 
extended to a period of several weeks, after which the solution was frozen down to form a matrix. However, no signals characteristic of a triplet state could be observed outside the central absorption by $\mathbf{1}^{3-}$, where such signals should be found upon reduction of a doublet-state radical (for relevant examples see [2] [10] [12]). This failure is probably due to the large distance $(1.3 \mathrm{~nm})$ between the two electrons, estimated as that between the centres of the two phane moieties. The zero-field splitting parameter predicted for such a distance is $1.4 \mathrm{mT}$ [13] [14], a value considerably smaller than the total spectral width of $2.1 \mathrm{mT}$ for $\mathbf{1}^{3-}$. As a consequence, the stronger $x, y$-components of the triplet-state signals would be completely masked by the spectrum of $\mathbf{1}^{3-}$, while their much weaker $z$-counterparts would be obscured by the wings of this spectrum ${ }^{2}$ ). Deuteriation of 1 at the benzene decks of the phane moieties should reduce the total spectral width of $1^{3-}$ to $0.6 \mathrm{mT}$ and uncover the presumed triplet-state signals of $\mathbf{1}^{4-}$. However, preparation of 1 labelled in these positions requires too great synthetic effort to be considered as a practicable procedure.

The location of spin and/or charge in the redox stages of $\mathbf{1}$ is schematically represented in Fig. 6.

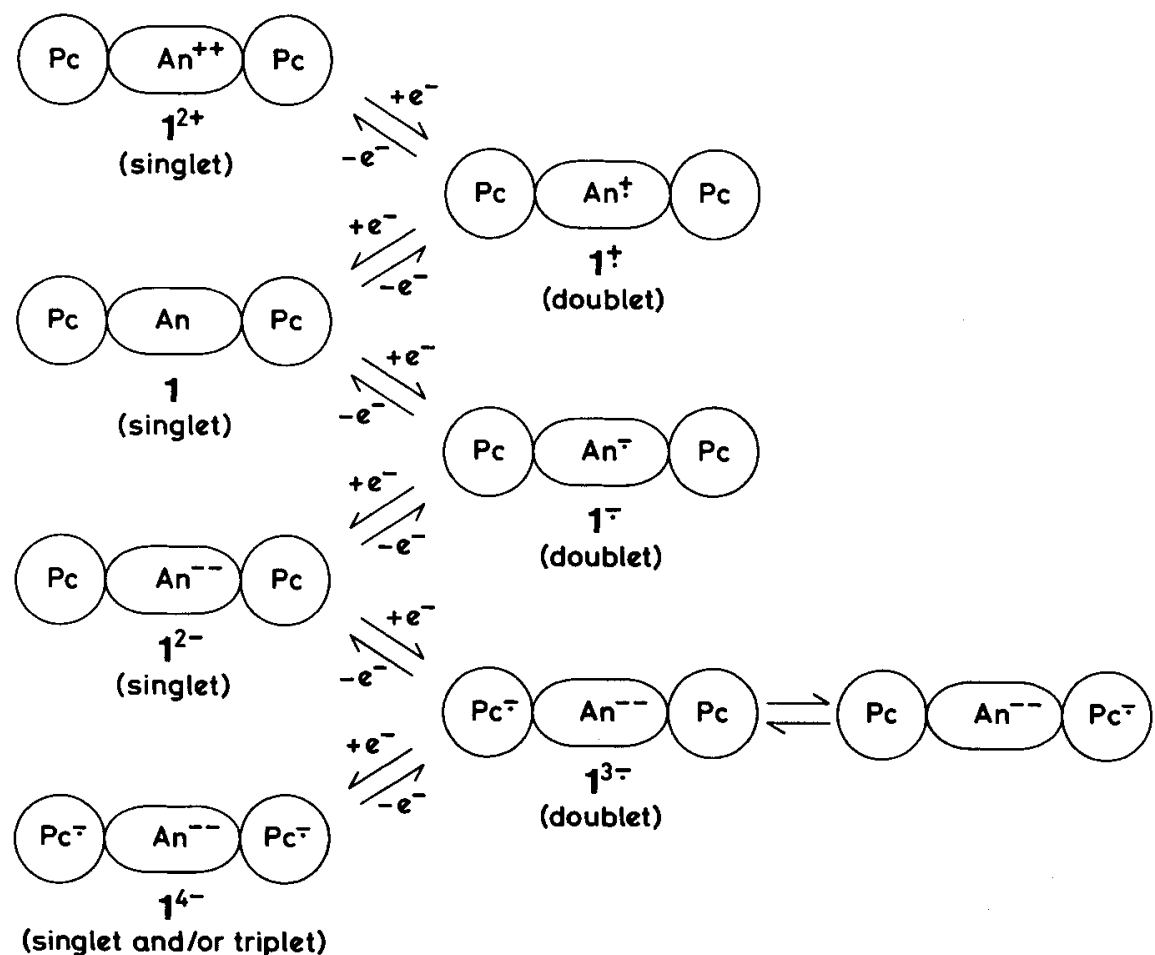

Fig. 6. Diagrammatic representation of the seven redox stages of 1 . An: anthracene; $\mathrm{Pc}:$ [2.2]paracyclophane.

${ }^{2}$ ) Triplet-state signals at half-field are, in general, not observable for large separation of two electrons [2] [12] [14]. 
Experimental. - Source of Compounds. Synthesis of the bisphane 1 has been described in [1] [15]. Dibutylanthracene 2 was synthesized according to a procedure reported in [16].

Instrumental. Cyclic voltammograms of 1,2 , and 3 were recorded on a $P A R$ potentiostat model 173 with programmer model 175 and on a Metrohm Polarecord E506 with VA Scanner E612/VA Stand 663. The experimental conditions, under which these data were obtained, are given in Table 3. ESR Spectra were taken on a Varian-E9 instrument, while a Bruker-ESP-300 system served for ENDOR and TRIPLE-resonance studies.

Table 3. Experimental Conditions for the Studies of 1, 2, and 3 by Cyclic Voltammetry

\begin{tabular}{lllllll}
\hline & $\begin{array}{l}\text { Working } \\
\text { electrode }\end{array}$ & $\begin{array}{l}\text { Auxiliary } \\
\text { electrode }\end{array}$ & Solvent & $\begin{array}{l}\text { Supporting } \\
\text { salt }\end{array}$ & $\begin{array}{l}\text { Temp. } \\
{[\mathrm{K}]}\end{array}$ & $\begin{array}{l}\text { Scan } \\
{[\mathrm{mV} / \mathrm{s}]}\end{array}$ \\
\hline Oxidation of 1 & $\mathrm{Pt}$ disc & Pt wire & $\mathrm{CH}_{2} \mathrm{Cl}_{2}$ & $\mathrm{Bu}_{4} \mathrm{NPF}_{6}$ & 298 & 100 \\
Reduction of $\mathbf{1}$ & $\mathrm{Pt}$ disc & $\mathrm{Pt}$ wire & $\mathrm{HNMe}_{2}$ & $\mathrm{Bu}_{4} \mathrm{NBr}$ & 233 & 100 \\
Oxidation of 2 & $\mathrm{Pt}$ disc & Pt wire & $\mathrm{CH}_{2} \mathrm{Cl}_{2}$ & $\mathrm{Bu}_{4} \mathrm{NClO}_{4}$ & 298 & 300 \\
Reduction of 2 & $\mathrm{HMDE}$ ) & graphite & $\mathrm{MeCN}$ & $\mathrm{Bu}_{4} \mathrm{NClO}_{4}$ & 298 & 300 \\
Reduction of 3 & $\mathrm{Pt}$ disc & Pt wire & DME/THF & $\mathrm{Bu}_{4} \mathrm{NBr}$ & 233 & 100 \\
\hline
\end{tabular}

a) HMDE = Hanging Mercury Drop Electrode.

This work was supported by the Schweizerischer Nationalfonds zur Förderung der wissenschaftlichen Forschung. We thank $U$. Buser of Basel laboratory for preparing a sample of 2.

\section{REFERENCES}

[1] B. König, J. Heinze, K. Meerholz, A. de Meijere, Angew. Chem. 1991, 103, 1350; ibid. Int. Ed. 1991, 30, 1361.

[2] A. de Meijere, F. Gerson, B. König, O. Reiser, T. Wellauer, J. Am. Chem. Soc. 1990, 112, 6827.

[3] R. Jund, P. Lemoine, M. Gross, Angew. Chem. 1982, 94, 312; ibid. Int. Ed. 1982, 21, 305.

[4] H. Kurreck, B. Kirste, W. Lubitz, 'Electron Nuclear Double Resonance Spectroscopy of Radicals in Solution', VCH Publishers, Inc., New York, 1988, Chapt. 2.

[5] F. Gerson, 'High-Resolution ESR Spectroscopy', J. Wiley and Verlag Chemie, New York-Weinheim, 1970, Chapt. 1.5.

[6] J. R. Bolton, A. Carrington, A. D. McLachlan, Mol. Phys. 1962, 5, 31.

[7] D. Bachmann, Z. Phys. Chem. (Frankfurt) 1964, 43, 198.

[8] I. H. Elson, J.K. Kochi, J. Am. Chem. Soc. 1973, 95, 5060; J.L. Courtneidge, A. G. Davies, J. E. Parkin, J. Chem. Soc., Chem. Commun. 1983, 1262.

[9] F. Gerson, W. B. Martin, Jr., H. N. C. Wong, C. W. Chan, Helv. Chim. Acta 1987, 70, 79.

[10] F. Gerson, B. Kowert, B. M. Peake, J. Am. Chem. Soc. 1974, 96, 118.

[11] P. Fürderer, F. Gerson, J. Heinzer, S. Mazur, H. Ohya-Nishiguchi, A. H. Schroeder, J. Am. Chem. Soc. 1979, 101, 2275; F. Gerson, Topics Curr. Chem. 1983, 115, 57.

[12] F. Gerson, W. Huber, W. B. Martin, Jr., P. Caluwe, T. Pepper, M. Szwarc, Helv. Chim. Acta 1984, 67, 416; F. Gerson, T. Wellauer, A. M. Oliver, M.N. Paddon-Row, ibid. 1990, 73, 1586.

[13] G. R. Luckhurst, in 'Spin Labeling: Theory and Applications', Ed. L. J. Berliner, Academic Press, New York, 1976, Chapt. 4.

[14] S. S. Eaton, K. M. More, B. M. Sawant, G. R. Eaton, J. Am. Chem. Soc. 1983, 105, 6560.

[15] B. König, Ph. D. Thesis, Universität Hamburg, 1991.

[16] A. I. Nogaideli, N. N. Skhirtladze, Soobshch. Akad. Nauk Gruz. SSR 1962, 29, 151; quoted in Chem. Abstr. $1963,58,5594$. 